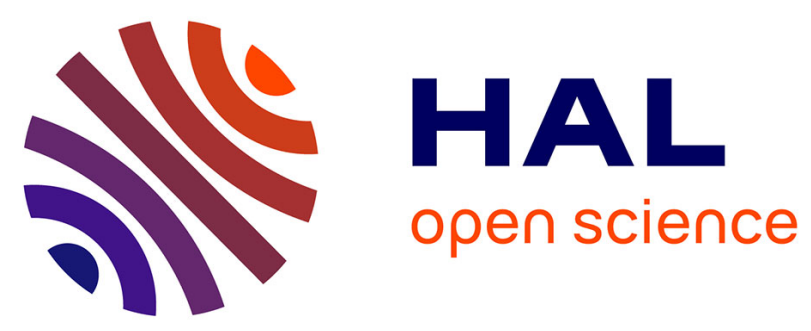

\title{
COMPARATIVE STUDY OF GexCx-1 FILMS PREPARED BY MOCVD FROM TETRAETHYLGERMANIUM AND TETRAVINYLGERMANIUM
}

M'B. Amjoud, A. Reynes, R. Morancho, P. Mazerolles, Robert Carles

\section{To cite this version:}

M'B. Amjoud, A. Reynes, R. Morancho, P. Mazerolles, Robert Carles. COMPARATIVE STUDY OF GexCx-1 FILMS PREPARED BY MOCVD FROM TETRAETHYLGERMANIUM AND TETRAVINYLGERMANIUM. Journal de Physique IV Proceedings, 1991, 02 (C2), pp.C2-327-C2334. 10.1051/jp4:1991240 . jpa-00249830

\section{HAL Id: jpa-00249830 https://hal.science/jpa-00249830}

Submitted on 1 Jan 1991

HAL is a multi-disciplinary open access archive for the deposit and dissemination of scientific research documents, whether they are published or not. The documents may come from teaching and research institutions in France or abroad, or from public or private research centers.
L'archive ouverte pluridisciplinaire $\mathbf{H A L}$, est destinée au dépôt et à la diffusion de documents scientifiques de niveau recherche, publiés ou non, émanant des établissements d'enseignement et de recherche français ou étrangers, des laboratoires publics ou privés. 


\author{
M'B. AMJOUD*, A. REYNES* ${ }^{*}$ R. MORANCHO* , P. MAZEROLLES** and \\ R. CARLES*** \\ * Laboratoire des Matériaux (URA 445 CNRS), Institut National \\ Polytechnique de Toulouse (E.N.S.C.T), 118 route de Narbonne, \\ F-31077 Toulouse cedex, France \\ * Laboratoire des Organometalliques (URA 477 CNRS), Université \\ Paul Sabatier, 118 route de Narbonne, F-31062 Toulouse cedex. \\ France \\ *** Laboratoire de Physique des Solides (URA 077 CNRS), \\ Université Paul Sabatier, 118 route de Narbonne, F-31062 \\ Toulouse cedex, France
}

\begin{abstract}
The coatings coming from the thermal decomposition of two organogermanium compounds $\mathrm{GeR}_{4}$ where $\mathrm{R}$ is either $\mathrm{C}_{2} \mathrm{H}_{5}$ or $. \mathrm{CH}=\mathrm{CH}_{2}$ have been investigated by various technics. According to the starting molecule and the experimental conditions, the films diplay different features. For example the pyrolysis of $\mathrm{Ge}\left(\mathrm{CH}=\mathrm{CH}_{2}\right)_{4}$ leads to the formation of a $\mathrm{Ge}-\mathrm{C}, \mathrm{C}-\mathrm{C}$ and $\mathrm{Ge}-\mathrm{Ge}$ bonds while the pyrolysis of $\mathrm{Ge}\left(\mathrm{C}_{2} \mathrm{H}_{5}\right)_{4}$ gives $\mathrm{Ge}-\mathrm{Ge}$ and few $\mathrm{C}-\mathrm{C}$ bonds.
\end{abstract}

\title{
1.- Introduction.
}

The interest in materials prepared from elements of the fourteenth column of the periodic table is well known and their field of applications is numerous. Among the techniques used to obtain thin films, chemical vapour deposition from organometallic compounds decomposition (O.M.C.V.D.) is one of the most versatile. Moreover to obtain a given material several chemical systems can be used. For example the preparation of thin films of amorphous $\mathrm{Si}_{\mathrm{X}} \mathrm{C}_{1-\mathrm{x}}$ alloys is carried out from various organometallic compounds (1) such as tetraethynylsilane : $\mathrm{Si}-(\mathrm{C} \cong \mathrm{CH})_{4}$ or tetrapropargyl silane $\mathrm{Si}-\left(\mathrm{CH}_{2}-\mathrm{C} \equiv \mathrm{CH}\right)_{4}$. The value of the composition $\mathrm{x}$ varies according to the type of the starting molecule, and particularly on the position of the triple bonds : $\mathrm{x}=0.82$ for the first molecule whereas $\mathrm{x}=0.24$ for the second. Indeed the nature of the material deposited depends on the mechanisms of pyrolysis and on the kinetics of the deposition. In order to improve our knowledge of the thermal behaviour of some organometallic precursors and try to find general rules of decomposition as a function of the radicals bonded to a metal $\mathrm{M}$ ( $\mathrm{Ge}, \mathrm{Si}, \mathrm{Sn}$ ) we have undertaken a study of the pyrolysis of organosilicon, organogermanium and organotin compounds $\mathrm{MR}_{4}, \mathrm{MR}_{2}^{\prime}$ where $\mathrm{R}$ is ${ }^{\mathrm{C}} \mathrm{C}_{2} \mathrm{H}_{5}$ or $\cdot \mathrm{CH}=\mathrm{CH}_{2}$, and $\mathrm{R}$ ' is $\cdot \mathrm{CH}=\mathrm{CH}-\mathrm{CH}=\mathrm{CH}$.

In all of the molecules the ratio $\mathrm{C} / \mathrm{M}$ is 8 , and only the structure of the radical change. This general work concerns the studies of the mechanisms of decomposition and the analytical and structural investigations of the materials deposited as a function of the precursors. The results presented in this paper only concerns the study of the films prepared by decomposition of tetraethylgermanium $\mathrm{Ge}\left(\mathrm{C}_{2} \mathrm{H}_{5}\right)_{4}(\mathrm{TEGe})$ and tetravinylgermanium $\mathrm{Ge}(\mathrm{CH}=\mathrm{CH})_{4}(\mathrm{TVGe})$.

\section{2.- Experimental details and growth kinetics.}

The decomposition of the two precursors TEGe and TVGe have been carried-out in a classical horizontal hot wall reactor which has been described elsewhere (2).

The experimental conditions used were the following : 


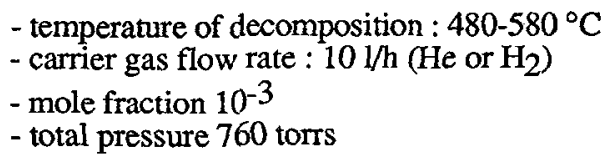

Various substrates have been chosen according to the physico-chemical technique used to characterize the films : intrinsic (111) silicon and silica (puropsil) $\mathrm{SiO}_{2}$ for Infra-Red investigations and for absorption in the UV, Visible, near Infra-Red regions respectively. For Raman and X-Ray Photoelectron Spectroscopies, either silicon or silica were used.

The thicknesses of the films prepared on silica were measured by means of a "Talystep" after etching of the material by a $10 \% \mathrm{HF}-90 \% \mathrm{HNO}_{3}$ solution. The values found are in the range : $0,8 \mu \mathrm{m}-3,5 \mu \mathrm{m}$. The variation of the growth rate as a function of the temperature are shown in the Arrhenius plot in figure 1 for TEGe decomposition and in figure 2 for TVGe. Two remarks are relevant :

$i$ - the growth rate from TVGe is higher than from TEGe in the temperature range investigated ii - for the two molecules, the growth rate is favoured by the use of hydrogen as carrier-gas.

The apparent energies of activation are given in Table I for each reaction.

Table-1 The apparent energies of activation $(\mathrm{Kcal} / \mathrm{mole})$ of tow precursors. * Ref/ $3 /$

\begin{tabular}{|c|c|c|}
\hline Precursors & TEGe & TVGe \\
\hline $\mathrm{He}$ & $34.3^{*}$ & 39 \\
\hline $\mathrm{H}_{2}$ & 41 & 28 \\
\hline
\end{tabular}

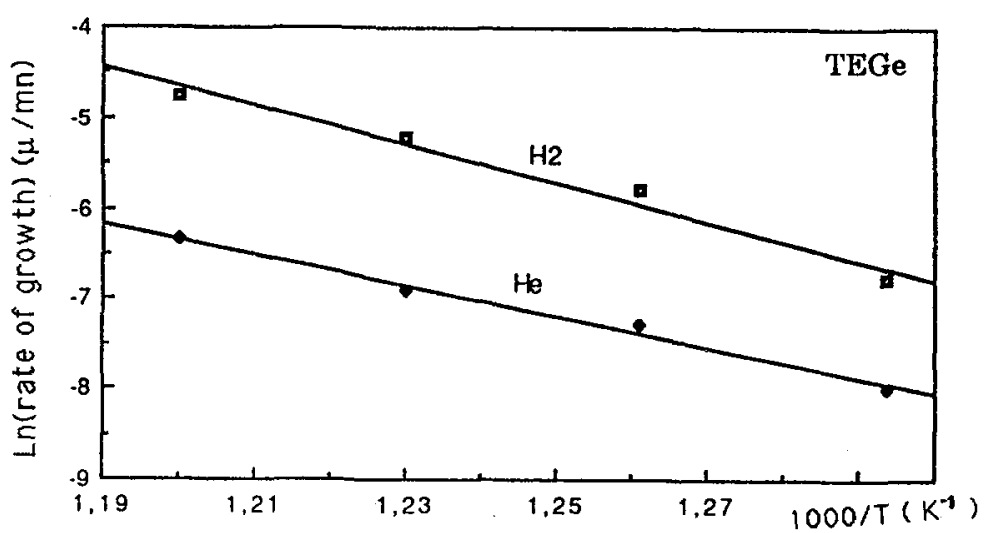

Fig.1. The growth rate of $\mathrm{Ge}_{\mathrm{x}} \mathrm{C}_{1-\mathrm{x}}$ from TEGe pyrolysis in Arrhenius plot 


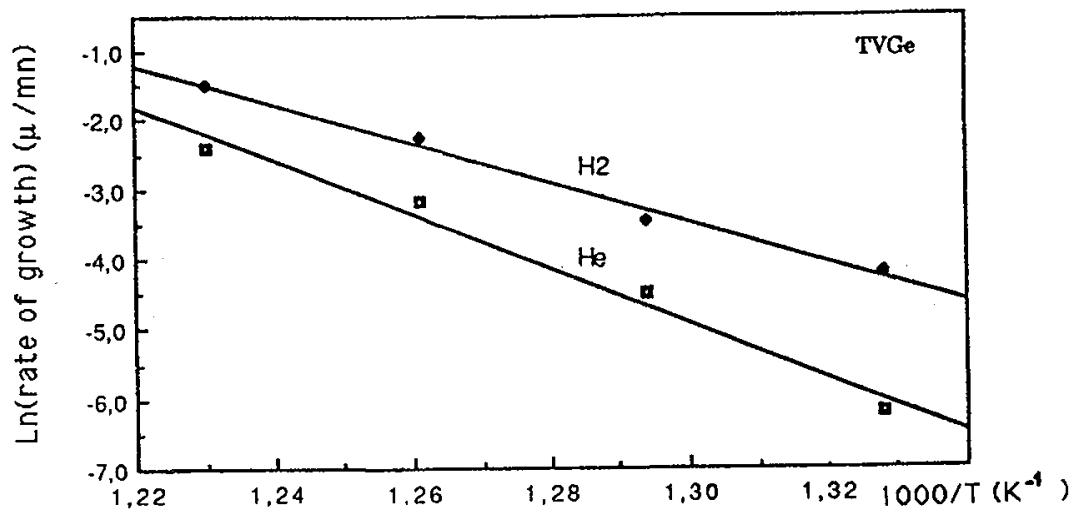

Fig.2. The growth rate of $\mathrm{Ge}_{\mathrm{x}} \mathrm{C}_{1-\mathrm{x}}$ from TVGe pyrolysis in Arrhenius plot.

\section{3.- Structural studies of the films.}

The structural characterization of the films has been performed by Infra-Red absorption (I.R.), X-ray Photoelectron Spectroscopy (X.P.S.) and Raman-Spectroscopy (R.S.).

\section{3.-1 Infra-Red absorption.}

The IR spectra of a film deposited at $560^{\circ} \mathrm{C}$ on intrinsic silicon substrates from TEGe thermal pyrolysis exhibits a wide band of weak intensity at around $1400 \mathrm{~cm}^{-1}$. This feature is attributed to the stretching vibration $\vee \mathrm{C}$-C. On the other hand in the same range of temperature the films prepared from TVGe display the two characteristic peaks of graphitic carbon $\left(1380 \mathrm{~cm}^{-1}\right.$ and $\left.1570 \mathrm{~cm}^{-1}\right)$. Moreover the IR spectra of these films present a strong band centered at $775 \mathrm{~cm}^{-1}$ (figure 3) which can be due either to the stretching of the $\mathrm{Ge}-\mathrm{C}$ bond $(4,5,6)$ or to the $\mathrm{GeO}$ bond $(7,8)$. In order to assign this band we have recorded the IR spectrum of an oxidized intrinsic germanium sample $\left(30 \mathrm{~min}\right.$ at $500^{\circ} \mathrm{C}$ under $\left.\mathrm{O}_{2}\right)$. This spectrum (figure 4) shows a strong absorption band at $875 \mathrm{~cm}^{-1}$ due to the Ge-O bonds. Consequently the peak located at 775 $\mathrm{cm}^{-1}$ in our solid phase comes from the presence of $\mathrm{Ge}-\mathrm{C}$ bonds. However, the presence of a shoulder towards higher energies is indicative of partial oxidization of the films.

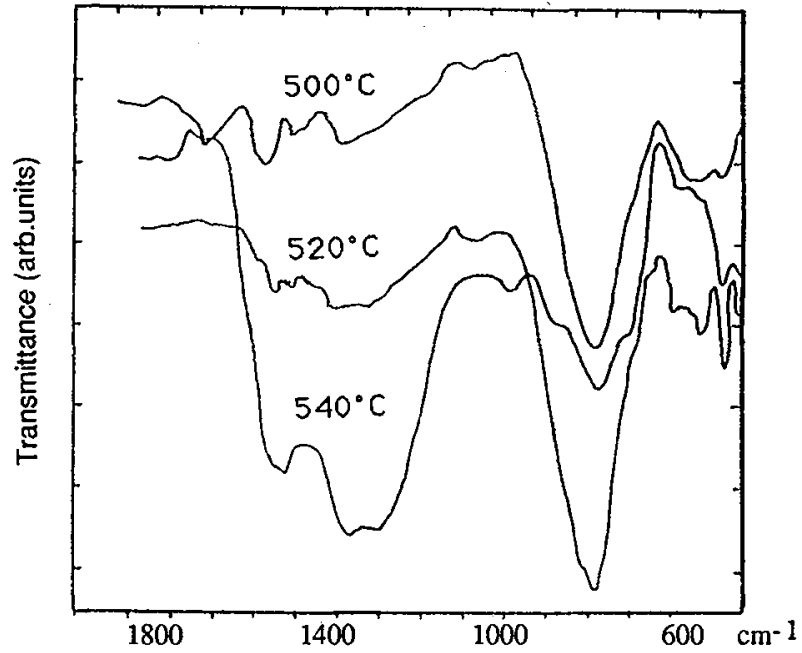

Fig. 3. I.R.absorption spectra of $\mathrm{Ge}_{\mathrm{x}} \mathrm{C}_{1-\mathrm{x}}$ at different temperatures of substrates from TVGe pyrolysis. 


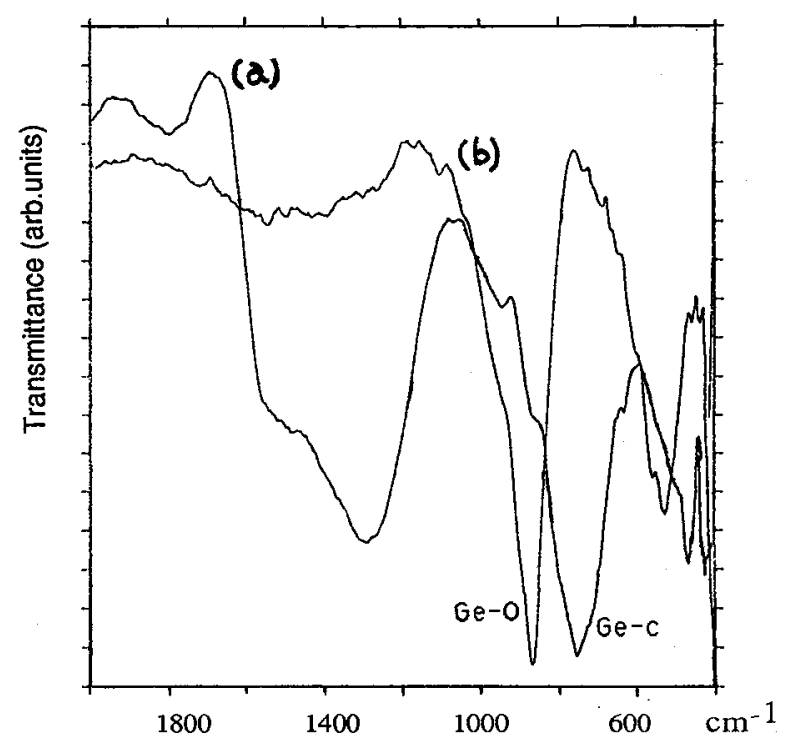

Fig.4. I R. absorption spectra of films: a) $\mathrm{Ge}_{\mathrm{X}} \mathrm{C}_{1-\mathrm{x}}$ prepared at $500^{\circ} \mathrm{C}$ under $\mathrm{He}$ from TVGe pyrolysis ; b) Intrinsec Ge oxidized at $500^{\circ} \mathrm{C}$ under $\mathrm{O}_{2}$

\section{3.-2 X-Ray Photoelectron Spectroscopy.}

X.P.S. spectra were recorded using monochromatic $A 1 \mathrm{~K} \alpha_{1,2}$ radiation (1486.6 eV) after removing the contamination layer by $\mathrm{Ar}^{+}$ion bombardment $(\mathrm{E}=6 \mathrm{Kv}, 100 \mathrm{~mA}$, during $20 \mathrm{~min})$. The energy of the gold $4 \mathrm{f} 7 / 2$ level $(84 \mathrm{eV})$ has been taken as reference. A typical spectrum of a sample obtained at $500^{\circ} \mathrm{C}$ from TVGe pyrolysis with He carrier gas is presented in figure 5. It reveals the presence of carbon, germanium and oxygen.

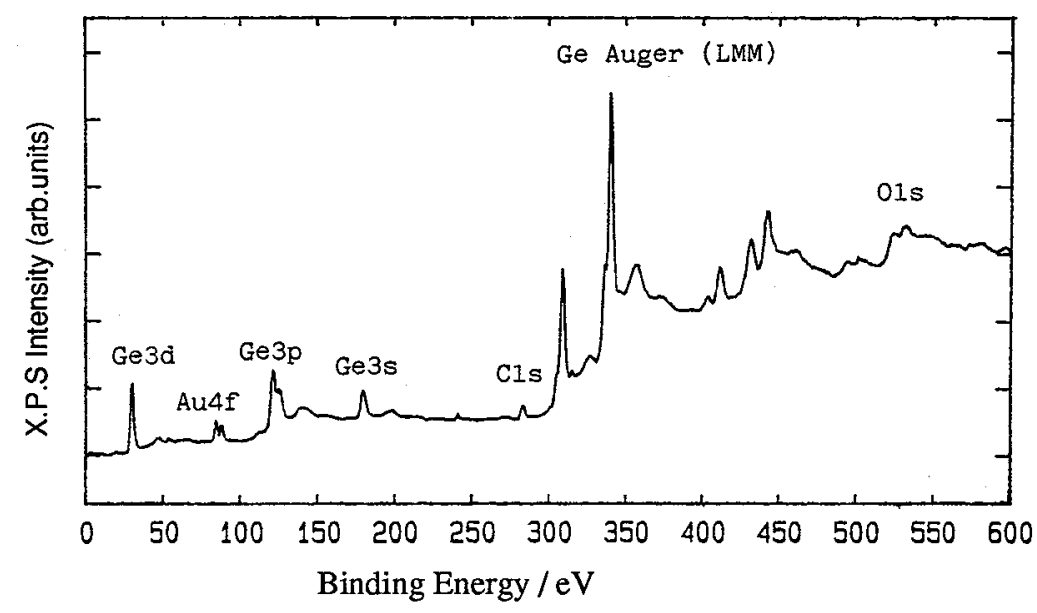

Fig.5. General XPS spectra of a coating obtained at $500^{\circ} \mathrm{C}$ under $\mathrm{He}$ from TVGe. 
The X.P.S. spectra of coatings obtained from TVGe decomposition display two peaks of C 1s (figure 6a) evidencing two kinds of environments : the peak located at $284.8 \mathrm{eV}$ is characteristic of $\mathrm{C}-\mathrm{C}$ bonds, and we assign the peak at $283.8 \mathrm{eV}$ to $\mathrm{C}$-Ge bonds. This last point is conforted by the presence of $\mathrm{Ge}-\mathrm{C}$ bonds revealed by the IR studies. Nevertheless the chemical shift of the Ge $3 \mathrm{~d}$ band pointed out in figure 7 betwen pure standard $\mathrm{Ge}$ (figure 7a) and the films prepared by thermal decomposition under $\mathrm{H}_{2}$ or $\mathrm{He}$ (figure $7 \mathrm{~b}$ and $7 \mathrm{c}$ respectively) is not significant to explain the chemical surrounding of Ge. As a matter of fact the variation of the Fermi level in the gap of $\mathrm{Ge}$ as a function of the doping level may be an explanation of these small shifts.The X.P.S. spectra of the $\mathrm{C} 1 \mathrm{~s}$ level recorded from the coatings prepared by TEGe decomposition only display one band centered at $284.5 \mathrm{eV}$. This feature is assigned to free carbon.

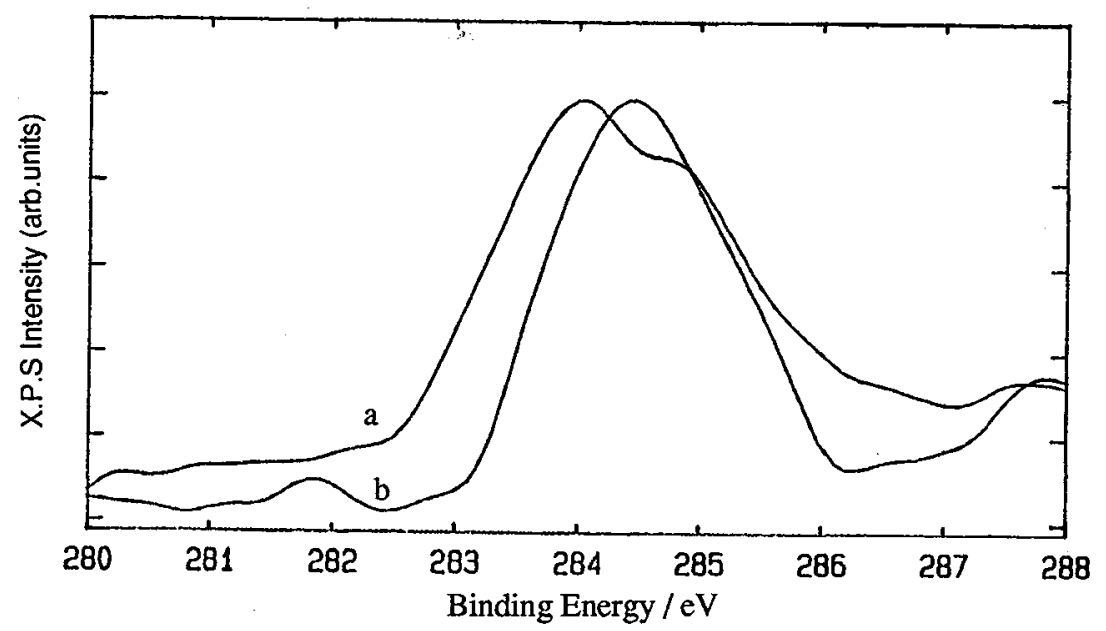

Fig.6. Binding energy of the $\mathrm{C} 1 \mathrm{~s}$ levels. Coating prepared at $500^{\circ} \mathrm{C}$ by pyrolysis of TVGe (a) and TEGe (b).

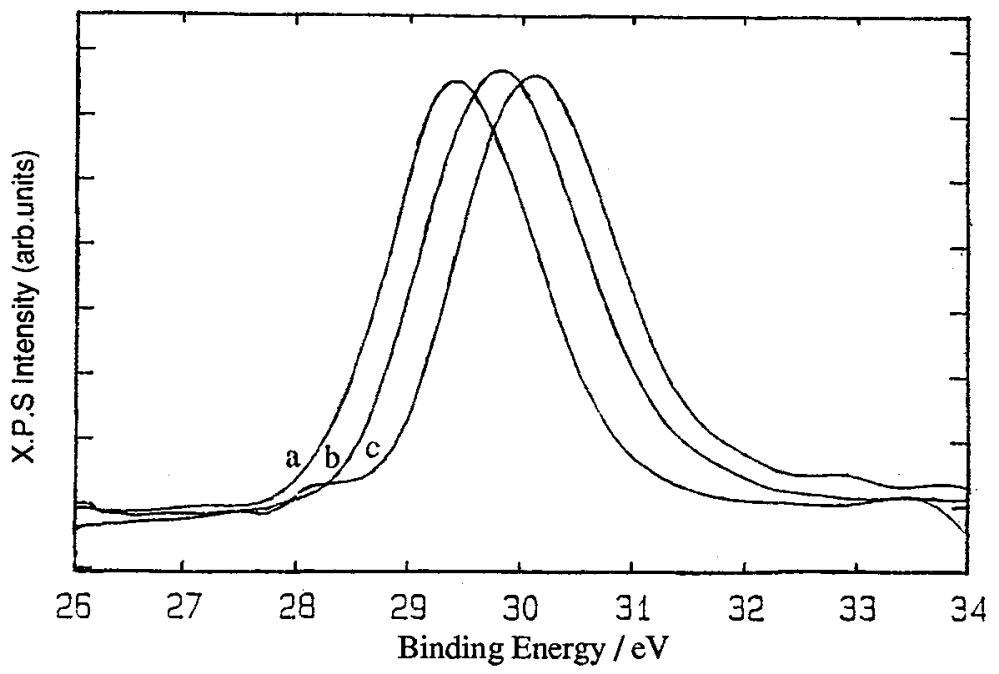

Fig.7. Binding energy of the Ge $3 d$ levels (a) standard sample (b) coating prepared from $\mathrm{TVGe}$ pytrolysis at $500^{\circ} \mathrm{C}$,(c) $520^{\circ} \mathrm{C}$. 


\section{3.-3 Raman Spectroscopy .}

In order to determine the crystalline quality of the films and to get further information on the local arrangements, we have performed Raman measurements. The spectra were recorded at room temperature using a grazing incidence, with the $488 \mathrm{~nm}$ line of an Ar laser as excitation. The signal was dispersed through a triple monochromator coupled to a conventional photon counting system. Typical spectra corresponding to the two types of precursors TVGe and TEGe, are reported in figures 8 and 9 respectively. Due to the low scattering efficiency of C-Ge bonds, we have only displayed the $\mathrm{Ge}-\mathrm{Ge}$ (250$\left.310 \mathrm{~cm}^{-1}\right)$ and the $\mathrm{C}-\mathrm{C}\left(1200-1700 \mathrm{~cm}^{-1}\right)$ optical bands. No influence of the nature of the substrate was detected. The Ge-Ge bond signature consists of a single band located around $300 \mathrm{~cm}^{-1}$. In the case of TVGe/He it evolves from a broad band centered at $275 \mathrm{~cm}^{-1}$ (figure $8 \mathrm{a}$ ) into an asymmetrical and narrower one at $295 \mathrm{~cm}^{-1}$ (figure $8 \mathrm{~b}$ ), by increasing the deposition temperature. Changing the nature of the gas $\left(\mathrm{He}\right.$ by $\mathrm{H}_{2}$ ) amplifies this evolution (figure $8 \mathrm{c}$ and $8 \mathrm{~d}$ ). At the highest temperature the spectrum exhibits a sharp and asymmetrical peak at $301.5 \mathrm{~cm}^{-1}$ which coïncides with the long wavelength optical mode $O(T)$ of crystalline Ge. Such an evolution $(a \rightarrow d)$ is characteristic of the enlarging of the size of crystallites in polycrystalline materials. From measurements of the full width at half maximum, one can deduce an average "Raman size" of the microcrystals. Whereas this size is less than few tenths $\AA$ in (a), it exceeds several hundreds $\AA$ in (d) (13). When TEGe is used (figure 9) whatever the growth conditions the crystalline nature of the Ge phase is more pronounced. In particular, at low temperature and using $\mathrm{He}$ (figure 9a), the amorphous like shape of the spectra (figure $9 \mathrm{~b}$ ) has disappeared.The signature of $\mathrm{C}-\mathrm{C}, \mathrm{sp}^{2}$ bonding (graphitic) consist of the two bands located at $1375 \mathrm{~cm}^{-1}$ and $1580 \mathrm{~cm}^{-1}$. The data reported in figure 8 and 9 show clearly that : (i) they are present when He is used as gas (a and b) ; (ii) their intensities rapidly decrease when the deposition temperature increases (a to b) ; (iii) the presence of a crystalline phase is favoured by the use of TVGe.

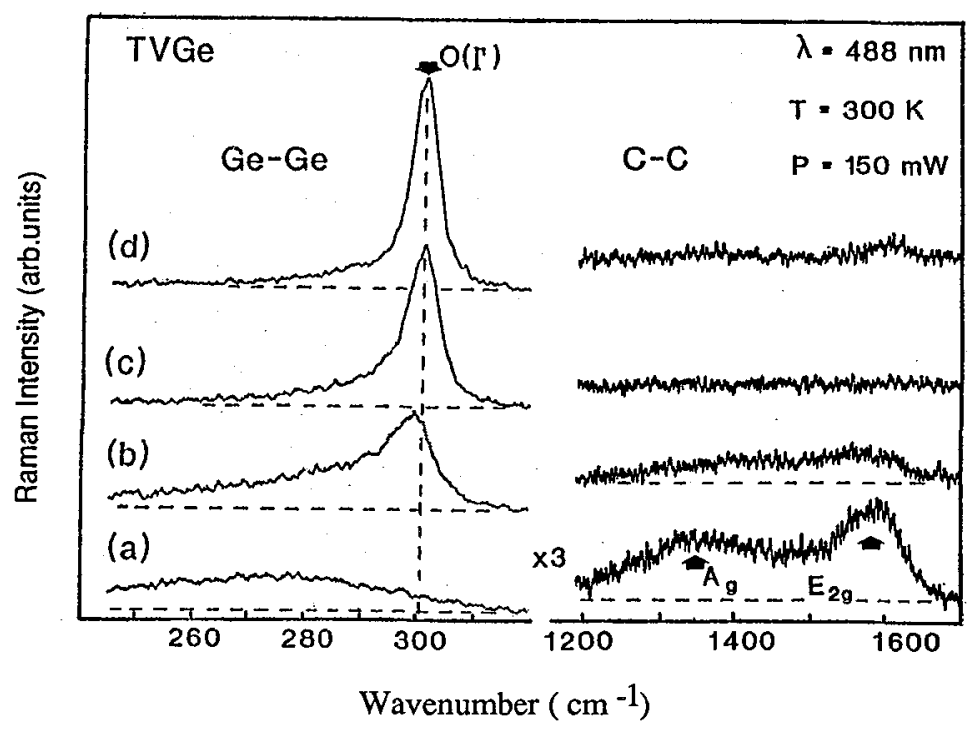

Fig.8. Typical Raman spectra of films grown using TVGe as precursor, $\mathrm{He}(\mathrm{a}, \mathrm{b})$ or $\mathrm{H}_{2}(\mathrm{c}, \mathrm{d})$ as gas at $500^{\circ} \mathrm{C}(\mathrm{a}, \mathrm{c})$ and $540^{\circ} \mathrm{C}(\mathrm{b}, \mathrm{d})$. 


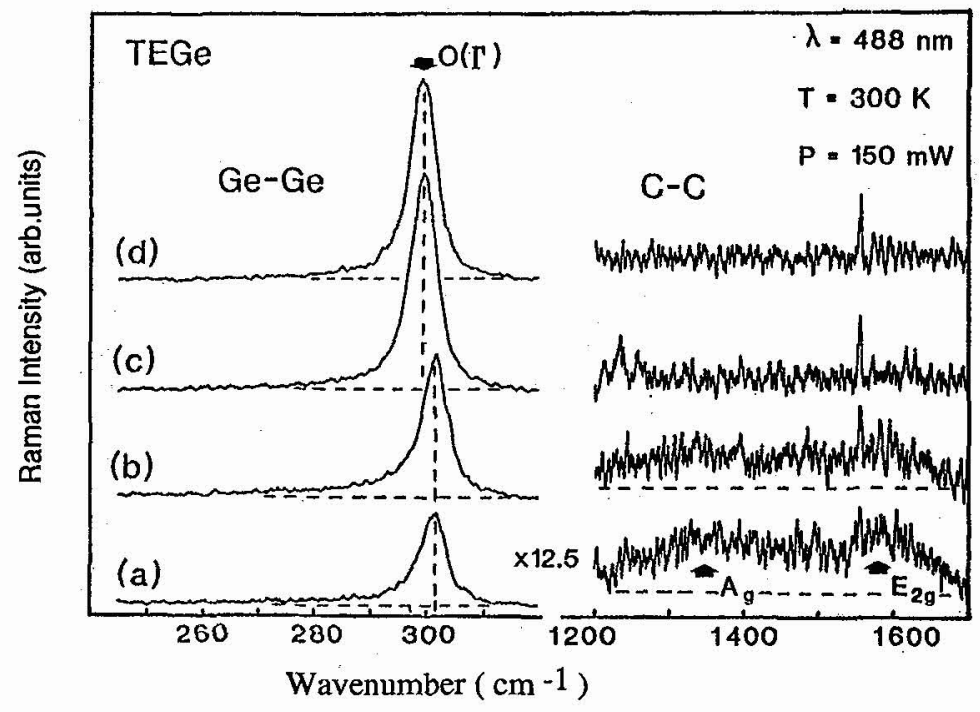

Fig.9. Typical Raman of films grown using TEGe as precursor, $\mathrm{He}(\mathrm{a}, \mathrm{b}$ ) or $\mathrm{H}_{2}(\mathrm{c}, \mathrm{d})$ as gas at $500^{\circ} \mathrm{C}(\mathrm{a}, \mathrm{c})$ and $540^{\circ} \mathrm{C}(\mathrm{b}, \mathrm{d})$.

\section{4.- Conclusion.}

The thermal decomposition of TEGe and TVGe lead to the formation of thin $\mathrm{Ge}_{\mathrm{x}} \mathrm{C}_{1-\mathrm{x}}$ films.

By using different techniques of investigations (XPS, RS and IR) there is evidence for the presence of three kinds of bonds $\mathrm{C}-\mathrm{C}, \mathrm{Ge}-\mathrm{Ge}$ and $\mathrm{Ge}-\mathrm{C}$. In particular, $\mathrm{Ge}-\mathrm{C}$ bonds have been revealed by $\mathrm{IR}$ spectroscopy. The carbon is present under a graphitic like phase with poor crystallization and whatever the precursor used it appears in the films at low temperature of decomposition and under He carrier gas.

At the same time, we observed an evolution of the crystallinity of the germanium phase in which grain sizes increase when the temperature goes up and when $\mathrm{H}_{2}$ is used as carried gas. The diminution of the presence of $\mathrm{C}$ and the crystallinity of $\mathrm{Ge}$ is more readily achieved with TEGe than with TVGe.

From these first results, it appears that the behaviour of precursors having identical C/Ge ratios are not the same. In particular, the materials obtained exhibit notable microstructural differences. However in order to complete this investigation, quantitative analysis $\mathrm{Ge}$ and $\mathrm{C}$ is necessary as well as a correlation with the gas phase decomposition and this will be investigated elsewhere. 


\section{References.}

/1/ Gerault, J.P. Morancho, R. and Constant, G. Mazerolles, P. and Manuel, G J. Anal and Appl. Pyrolysis, 4 (1982) 59

12/ Morancho, R. Reynes, A. and Mazerolles, P.

Silicon germanum, tin, and lead compounds 2 (1986) 155

13/ Avigal, Y. Itzhak, D. and Schieber, M.

J. Electrochem. Soc 9 (1975) 1226

14/ Catherine, $Y$. and Turban, G.

Thin solid films $\underline{70}$ (1980) 101

15/ Morimoto, Kataoka, T., Kumeda, M. and Shimizu T.

Phil. Mag. B50 (1984) 517

16) Shinar, J. Wu, H.S. Shinar, R. and Shanks, $H$. J. Appl. Phys. 62 (1987) 808

तI Lucovsky, G. Chao, S.S. Yang, J. Tyler, J.E. Ross, R.C. and Czubatyje, G. J. Phys. Rev. B31 (1985) 2190

/8/ J. Shiatshvili, D.A. and Kutelia

Phys. State Solid B143 (1987) K147

19/ Lucovsky, G. Chao, S.S. Tyler, J.E. and De Maggio, G. J. Vac. Sci. Technol. 21 (1982) 838

/10/ Arghavani, M.R. Braunstein, R. Chalmers, G. Shirun, D. and Yang, P. Solid State Comm. 71 (1989) 599

/11/ Gerault, J.P. Morancho, R. and Constant, G. Thin Solid Films 101 (1983) 83

/12/ Taylor, P.A. Bozack, M. Choyke, W.J. and Yates, J.T. J. Appl. Phys. 65 (1989) 1099

/13/ Fujii, M. Hayashi, S. and Yamamoto, K. Appl. Phys. Lett. 57 (1990) 2692

/14/ Elman, B.S. Dresslhaus, M.S. Dresselkhaus, G. Maby, E.W. and Mazurek, H. Phys. Rev. B24 (1981) 1027 